\title{
Measuring Attrition of L2 Productive Vocabulary Knowledge Over the Summer Vacation
}

\author{
Brandon Kramer ${ }^{\mathrm{a}}$, Tohru Matsuo ${ }^{\mathrm{b}}$, Aaron C. Sponseller ${ }^{\mathrm{b}}$, \\ Young Ae Kim ${ }^{\mathrm{c}}$, Suzuka Nishiyama ${ }^{\mathrm{d}}$, and Stuart McLean ${ }^{\mathrm{d}}$ \\ ${ }^{a}$ Kwansei Gakuin University; ${ }^{b}$ Osaka Jogakuin University \& Junior College; \\ 'Kyoto Seika University; 'Momoyama Gakuin University
}

\begin{abstract}
For many teachers and administrators, the degree to which attrition over summer vacation represents a threat to instructed language acquisition remains unclear. In a previous study, Kramer et al. (2019) looked at receptive vocabulary knowledge attrition over summer vacation, found no evidence of attrition using these measures, and called for future research to instead use tests of productive vocabulary knowledge which is more likely to be forgotten. Therefore, in this study we investigate the amount of summer attrition among Japanese university students $(N=81)$ and any mediation in that attrition attributable to digital paired-associate vocabulary studying, extensive reading, or experience travelling abroad. The results indicate that although there was no significant group difference in pre- and post-test productive vocabulary scores, a small but significant relationship was found between digital paired-associate vocabulary studying and vocabulary test score gains.
\end{abstract}

Keywords: Vocabulary, attrition, summer attrition, productive vocabulary knowledge

\section{Background and Aim}

The degree to which attrition over summer vacation represents a threat to instructed language acquisition remains unclear for many teachers and administrators. This study investigates that threat with regard to productive vocabulary knowledge studied through a coordinated vocabulary program. In a previous study, Kramer et al. (2019) found no evidence of receptive vocabulary knowledge attrition over summer vacation. They called for future research to instead use tests of productive vocabulary knowledge, which is more likely to be forgotten (Schmitt, 2010; Weltens \& Grendel, 1993).

The following research questions were developed:

1. To what extent can systematic attrition be detected in Japanese university students' L2 productive vocabulary knowledge after a 2-month summer break?

2. Is there a relationship between changes in L2 productive vocabulary knowledge and review using a digital paired-associate vocabulary study application, words read through extensive reading, or experience travelling abroad?

3. What patterns can be found in the attrition of partial vocabulary knowledge over a 2-month summer break? 


\section{Methodology}

\subsection{Participants}

The participants $(N=81)$ for this study were first-year university students at a private women's university in western Japan. The mean TOEIC score, calculated from those which were available was $351.4(S D=73.7, n=74)$. All students studying at this institution participated in a school-wide vocabulary programme that covers the New General Service List (NGSL) (Browne et al, 2013) using a digital paired-associate flashcard and testing application called Vocabulary Builder (EnglishCentral, 2019). According to the university curriculum, all students study a little more than 500 words of the NGSL in their first semester, as shown in Table 1 below.

In addition to the vocabulary programme, all first-year students must read graded readers as part of an extensive reading programme using an online application called Xreading.com (Goldberg, 2019). The curricular goals of this extensive reading program are also presented in Table 1. Graded readers are written using easy and frequent vocabulary. Thus, they are thought to potentially have an effect on vocabulary retention over the summer vacation. The number of words which a student is counted as having read are only for those books for which they have scored over $60 \%$ on an associated follow-up comprehension test.

\subsection{Instruments}

For the measurement of productive vocabulary knowledge, an online vocabulary testing site called VocabLevelTest.org was used (McLean \& Raine, 2019). Using this website, the participants were tested on their ability to accurately produce the English forms of words based on prompts that include the Japanese definition and an example sentence. An example prompt can be seen in Figure 1.

Students had 30 seconds to answer each question and the time remaining was indicated by a progress bar below the item prompt. They also had the option to skip the question if they had no knowledge of the target form. One complication of a form-recall test such as this is that there are sometimes multiple possible correct answers for a particular Japanese meaning and example sentence. Therefore, if they typed a word that was associated with the Japanese meaning, but was not the target word being tested, a prompt appeared asking the participant to try to produce the target word form again. Such a prompt is displayed in Figure 2.

Table 1. First-Year Curriculum with Regard to Vocabulary Study and Extensive Reading

\begin{tabular}{llll}
\hline Program & First semester & Summer Vacation & Second Semester \\
\hline English Central & NGSL 501-1008 & Voluntary review & NGSL 1001-1507 \\
Vocabulary Builder & 180,000 words & $\begin{array}{l}\text { Voluntary reading which counts } \\
\text { towards second semester goals }\end{array}$ & $\begin{array}{l}\text { 180,000 words for } \\
\text { full points }\end{array}$ \\
\hline
\end{tabular}

Note. NGSL = New General Service List (Browne et al., 2013). 
Figure 1. Example Form-Recall Vocabulary Item from VocabLevelTest.org.

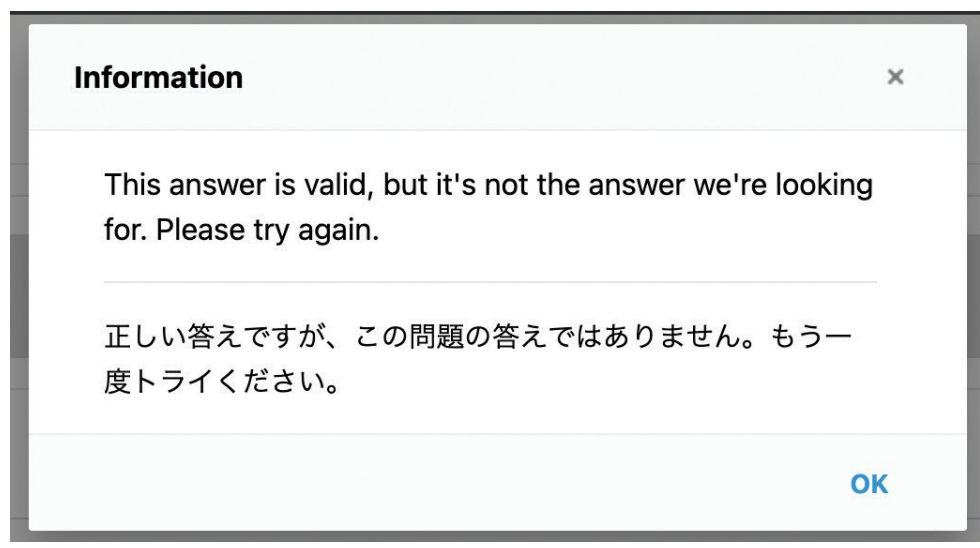

Figure 2. Prompt Telling Students to Make Another Attempt at the Target Word.

The target words tested were 30 randomly selected words each from bands 2 and 3 of the NGSL (frequency ranks 501-1507), for 60 words in total. The same words were tested on the pre- and post-tests. A list of the tested words is shown in Appendix A.

Although the website automatically scores the items dichotomously using a continually growing bank of acceptable answers, in order to measure partial knowledge the results were coded by two native speakers of Japanese who are highly proficient in English. The items were coded as belonging to one of the five categories as shown below $(\kappa=0.75$; agreement $=84.6 \%)$.

A. Correct target word, with correct spelling and derivational form

B. Correct target word and derivational form, but with incorrect spelling

C. Correct target word and spelling, but with incorrect derivational form

D. Spelling and derivational form are incorrect, but demonstrated some knowledge of the target word

E. No demonstrated knowledge of the target word

In order to conduct the quantitative analyses for research questions 1 and 2, these categories were collapsed into a partial credit model where full points (2) 
were assigned for perfect responses (category A only). Partial credit points (1) were assigned for responses which demonstrated any kind of partial knowledge (categories B, C, and D). Zero points were assigned for responses that were coded as containing no demonstrated knowledge of the target word (category E).

\subsection{Procedures}

The students completed the productive vocabulary pre-test on the final day of classes in the spring semester with instructions to study over the summer vacation in order to maintain their English proficiency. Specifically, all the students were instructed to continue reviewing vocabulary using Vocabulary Builder and to read as much as they could using Xreading.com. During the first class of the fall semester, the students completed the productive vocabulary post-test as well as a survey collecting background information such as TOEIC scores, summer study habits, and whether they travelled to any foreign countries during the semester break.

\section{Results}

To detect any productive vocabulary knowledge attrition between the preand post-test, a paired samples $t$-test was conducted using the collapsed categories described previously in JAMOVI (The JAMOVI Project, 2021). No statistically significant difference was found, $t(80)=0.12, p=0.902, d=0.01$. Descriptive statistics for both the tests can be found in Table 2, with the distribution of score differences shown in Figure 3.

Over the summer vacation, only a limited number of students continued studying as recommended, either via Vocabulary Builder $(n=56 ; 69 \%$ of the sample) or Xreading ( $n=55 ; 68 \%$ of the sample). See Table 3 for the descriptive statistics for these activities. Even fewer students visited foreign countries during the summer vacation ( $n=18 ; 22 \%$ of the sample). A multiple linear regression was conducted in JAMOVI (The JAMOVI Project, 2021) to predict the change in vocabulary scores based on the number of reviews using Vocabulary Builder, the number of running words read using Xreading, and international travel. The variables were added in the order of predicted importance (vocabulary review first, followed by words read in Xreading, and finally a dummy code indicating international travel), but only vocabulary review using Vocabulary Builder was retained in the model because of its significant relationship with gains from pre- to post-test, $F(1,79)=3.99, p=0.049, R^{2}=4.9 \%$.

Finally, the response data for all the participants were analysed using the original 5-category codes to learn exactly where any attrition was taking place.

Table 2. Descriptive Statistics for the Pre- and Post- Test Productive Vocabulary Scores

\begin{tabular}{lccccccccccc}
\hline & Min & Max & $M$ & SEM & Median & SD & Skew & SES & Kurt & SEK & $\alpha$ \\
\hline Pre-test & 15 & 64 & 35.8 & 1.30 & 36 & 11.7 & 0.31 & 0.27 & -0.45 & 0.53 & 0.807 \\
Post-test & 12 & 65 & 35.7 & 1.38 & 35 & 12.5 & 0.17 & 0.27 & -0.72 & 0.53 & 0.828 \\
\hline
\end{tabular}

Note. $N=81 ;$ SEM = Standard Error of Mean; SES = Standard Error of Skewness; SEK = Standard Error of Kurtosis. 


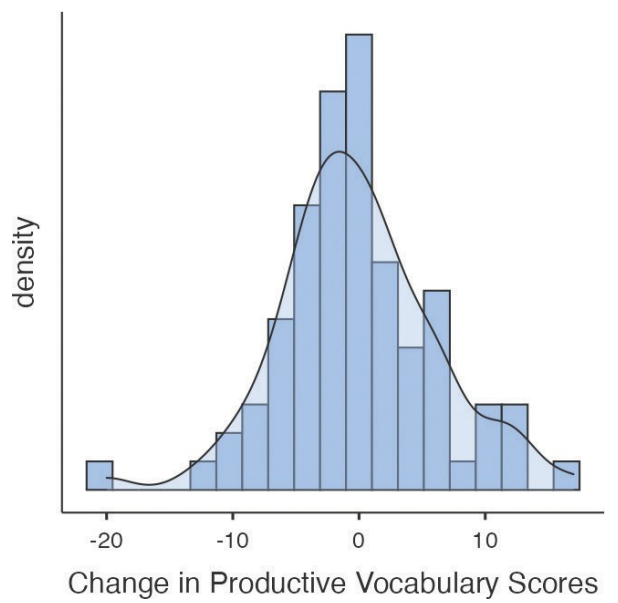

Figure 3. Distribution of Changes in Scores between Pre- and Post-Test Measures.

Table 3. Descriptive Statistics for ER Words Read and Vocabulary Reviews Over the Summer

\begin{tabular}{lcccccccccc}
\hline & Min & Max & $M$ & SEM & Median & SD & Skew & SES & Kurt & SEK \\
\hline Words Read & 0 & 120,150 & 14,813 & 2,558 & 2,911 & 23,018 & 2.02 & 0.27 & 4.74 & 0.53 \\
Vocab Reviews & 0 & 4,886 & 449 & 107 & 15 & 963 & 2.78 & 0.27 & 8.00 & 0.53 \\
\hline
\end{tabular}

Note. $N=81 ;$ SEM = Standard Error of Mean; SES = Standard Error of Skewness; SEK = Standard Error of Kurtosis.

Table 4. Breakdown of Categorical Attrition between Pre- and Post-Test

\begin{tabular}{lc}
\hline & Attrition (\% of Total Responses) \\
\hline$A \rightarrow B$ & $11(0.09 \%)$ \\
$A \rightarrow C$ & $49(0.40 \%)$ \\
$A \rightarrow D$ & $4(0.03 \%)$ \\
$A \rightarrow E$ & $3(0.02 \%)$ \\
$B \rightarrow D$ & $29(0.24 \%)$ \\
$B \rightarrow E$ & $48(0.40 \%)$ \\
$C \rightarrow D$ & $20(0.17 \%)$ \\
$C \rightarrow E$ & $23(0.19 \%)$ \\
$D \rightarrow E$ & $11(0.09 \%)$ \\
Total & $198(1.63 \%)$ \\
\hline
\end{tabular}

Note. Total number of items answered $=12,120$. Changes from $\mathrm{B} \rightarrow \mathrm{C}$ and $\mathrm{C} \rightarrow \mathrm{B}$ were not counted as they do not clearly represent gain or attrition.

The results are shown in Table 4. Of the total words answered by all participants, $84.60 \%(10,249$ out of 12,115$)$ showed no change between the pre- and post-tests. The two most common attrition patterns were $A$ to $C$, in which target words were answered perfectly on the pre-test (A) but did not include the correct derivational form on the post-test (C), and B to E, in which the participants spelled target words 
incorrectly on the pre-test (B) and demonstrated no knowledge on the post-test (E). Both the $\mathrm{A}$ to $\mathrm{C}$ and the $\mathrm{B}$ to $\mathrm{E}$ patterns made up $0.4 \%$ of the total responses. Noteworthy, however, is the extremely low amount of attrition as a percentage of all student responses, $1.63 \%$.

\section{Discussion}

The first research question asked if there was any systematic attrition in the students' L2 productive vocabulary knowledge after a 2-month summer break. We found no evidence of such attrition using a paired samples $t$-test of pre- and post-test scores on a vocabulary levels test targeting the NGSL. This is good news. It indicates attrition is difficult to detect over the summer vacation even when using a stringent form-recall vocabulary levels test as we did in this study.

The second research question asked if there is a relationship between changes in this vocabulary knowledge and review using a digital paired-associate vocabulary study application, words read through extensive reading, or experience travelling abroad. We found a significant but small relationship between digital paired-associate vocabulary review and gains on the post-test, with about 0.143 points predicted for every 100 vocabulary reviews. Students must therefore spend a considerable amount of time conducting many reviews if they wish to see noticeable gains on a test such as this over the summer vacation.

The final research question asked if any patterns could be found in the attrition of partial knowledge. With only $1.68 \%$ of all the items showing attrition from pre- to post-test, these results reaffirm the conclusion that attrition seems to be a minimal concern over summer vacation.

\section{Limitations}

The conclusions of this study are limited by weaknesses in the research design. Although students who reviewed vocabulary over the summer vacation studied the frequency bands which contain the target words on the pre- and post-tests, they might not have reviewed those exact words during the summer vacation, depending on the specific words which were brought up by the algorithm within Vocabulary Builder. Similarly, those students who engaged in extensive reading or travelled abroad might not have been exposed to the target words at all. Future research could make sure that these words were included in their summer review, and administer tests unique to each student based on the specific words which were reviewed.

Furthermore, while the target words on both the tests were chosen from the frequency range which was studied during the first year of university, many of these words were likely already well known by some of the participants, making them more resistant to decay, or never learned at all, making attrition impossible. Future studies could control this by measuring the knowledge of only words which were learned during the first semester.

Finally, the extent to which the students in our sample are representative of Japanese university students more generally is unknown. Our sample was drawn 
from students at a university where English education is considered a central curricular pillar. Students at other universities may not study English nearly as much during the academic semesters or during summer vacations. Therefore, future research might look to replicate this study in a more typical Japanese university context in which English education is compulsory but not necessarily prioritized.

\section{Conclusion}

In a previous study, Kramer et al. (2019) looked at student attrition over the summer vacation with regard to the students' ability to recognize and recall the meanings of L2 word forms that they studied during the school year. No systematic patterns of attrition were found, but it was theorized that if attrition were to take place over such a short period, tests of productive vocabulary knowledge, specifically requiring the recall of the $\mathrm{L} 2$ word forms, would be required to detect it. This study therefore measured the form-recall productive knowledge of students before and after summer vacation, but could not find any evidence of systematic attrition among the student sample. Furthermore, if the students wish to increase their vocabulary knowledge over this 2-month break, digital paired-associate vocabulary review (e.g., digital flashcard software) seems to be one way they could do this. But, based on the results of this study it will require a sizable effort to make any noticeable gains, with a 5-point gain in vocabulary test scores requiring an estimated 3,500 reviews.

\section{References}

Browne, C., Culligan, B., \& Phillips, J. (2013). The New General Service List. http:// www.newgeneralservicelist.org

EnglishCentral. (2019, November 14). EnglishCentral launches new comprehensive vocabulary learning system. EnglishCentral Solutions. https://solutions.englishcentral.com/2019/11/14/englishcentral-launches-new-comprehensivevocabulary-learning-system/

Goldberg, P. (2019). Xreading.com [Web Application]. https://xreading.com/

Kramer, B., Matsuo, T., McLean, S., \& Cornwell, S. (2019). Measuring attrition of L2 receptive vocabulary knowledge over the summer vacation. Vocabulary Education and Research Bulletin, 6(1), 17-22.

McLean, S., \& Raine, P. (2019). VocabLevelTest.Org [Web application]. https:// www.vocableveltest.org

Schmitt, N. (2010). Researching vocabulary: A vocabulary research manual. Palgrave Macmillan.

The JAMOVI Project (2021). JAMOVI (Version 1.6) [Computer Software]. https:// Www.jamovi.org

Weltens, B., \& Grendel, M. (1993). Attrition of vocabulary knowledge. In R. Schreuder \& B. Weltens (Eds.), The bilingual lexicon (Vol. 6, pp. 135-156). John Benjamins Publishing Company. 
Appendix A

List of NGSL Words Tested

\begin{tabular}{|c|c|c|c|c|c|}
\hline Band & Word & Rank & Band & Word & Rank \\
\hline 2 & education & 531 & 3 & invite & 1026 \\
\hline 2 & serve & 534 & 3 & copy & 1035 \\
\hline 2 & range & 516 & 3 & handle & 1039 \\
\hline 2 & standard & 547 & 3 & conduct & 1052 \\
\hline 2 & similar & 594 & 3 & collect & 1067 \\
\hline 2 & poor & 618 & 3 & appeal & 1071 \\
\hline 2 & manager & 661 & 3 & collection & 1082 \\
\hline 2 & necessary & 676 & 3 & alternative & 1088 \\
\hline 2 & average & 690 & 3 & software & 1089 \\
\hline 2 & yesterday & 703 & 3 & warning & 1130 \\
\hline 2 & behaviour & 706 & 3 & concept & 1211 \\
\hline 2 & population & 710 & 3 & refused & 1207 \\
\hline 2 & review & 730 & 3 & reform & 1213 \\
\hline 2 & despite & 771 & 3 & solve & 1219 \\
\hline 2 & solution & 788 & 3 & reaction & 1229 \\
\hline 2 & pressure & 809 & 3 & bottom & 1240 \\
\hline 2 & modern & 808 & 3 & colleague & 1249 \\
\hline 2 & avoid & 850 & 3 & attract & 1296 \\
\hline 2 & refer & 865 & 3 & twice & 1306 \\
\hline 2 & basis & 908 & 3 & relatively & 1324 \\
\hline 2 & speech & 893 & 3 & actual & 1333 \\
\hline 2 & encourage & 911 & 3 & opposite & 1371 \\
\hline 2 & earn & 925 & 3 & stone & 1372 \\
\hline 2 & professional & 935 & 3 & soldier & 1376 \\
\hline 2 & memory & 938 & 3 & hate & 1378 \\
\hline 2 & maintain & 942 & 3 & carefully & 1384 \\
\hline 2 & daily & 954 & 3 & totally & 1394 \\
\hline 2 & fix & 972 & 3 & army & 1416 \\
\hline 2 & cross & 974 & 3 & familiar & 1443 \\
\hline 2 & legal & 977 & 3 & arrangement & 1458 \\
\hline
\end{tabular}

